\title{
Nerve growth factor regulates the expression of vascular endothelial growth factor in human HaCaT keratinocytes via PI3K/mTOR pathway
}

\author{
J. Zhang ${ }^{1}$ and W.Y. Ma ${ }^{2}$ \\ ${ }^{1}$ Medical College, Shandong University, Jinan, Shandong, China \\ ${ }^{2}$ Department of Dermatology, Qilu Hospital of Shandong University, Jinan, China \\ Corresponding author: W.Y. Ma \\ E-mail: JinZHANG6@yeah.net
}

Genet. Mol. Res. 13 (4): 9324-9335 (2014)

Received June 5, 2013

Accepted November 29, 2013

Published January 24, 2014

DOI http://dx.doi.org/10.4238/2014.January.24.14

\begin{abstract}
Decades of research have provided the data to confirm the hypothesis that there is bidirectional communication between the central nervous system and the immune system in psoriasis pathogenesis, but the contribution of the cutaneous neural system remains underexplored. In this study, we evaluated the molecular mechanisms by which nerve growth factor (NGF) regulates hypoxia-inducible factor-1 $\alpha$ (HIF-1 $\alpha$ ) and vascular endothelial growth factor (VEGF) production. The mRNA and protein levels of VEGF secretion from HaCaT cells by NGF were increased in a concentration-dependent manner. In addition, the NGFinduced increase in VEGF is accompanied by an increase in HIF-1 $\alpha$, but not HIF- $2 \alpha$ or HIF-1 $\beta$. However, this increase is abrogated by pretreatment with a mammalian target of rapamycin (mTOR) inhibitor rapamycin. Pharmacologic inhibitors of the Trk tyrosine kinase, PI-3 kinase, and mTOR pathways prevent NGF-stimulated increases in HIF$1 \alpha$ and VEGF. Mutation of the siRNA-mediated silencing of HIF-1 $\alpha$ expression blocks NGF-induced increases in VEGF transcription. Our
\end{abstract}


study indicates that NGF regulates the expression of VEGF through the $\mathrm{PI} 3 \mathrm{~K} / \mathrm{mTOR}$ signaling pathway in human $\mathrm{HaCaT}$ keratinocytes.

Key words: Nerve growth factor; Hypoxia-inducible factor- $1 \alpha$; Psoriasis; Vascular endothelial growth factor; Keratinocytes

\section{INTRODUCTION}

Psoriasis is a common, chronic skin disease characterized by recurrent erythematous skin plaques that exhibit epidermal hyperplasia, variable inflammatory cell infiltrate, impaired epidermal differentiation, and accumulation of distinct leukocyte subpopulations (Menter and Griffiths, 2007; Nestle et al., 2009). Great advances have been made in understanding the roles of the immune system and the epidermal components of this skin disease, whereas the contribution of the cutaneous neural system remains underexplored. Numerous observations suggest that the nervous system may play a role in this disease, including the symmetrical distribution of plaque on the body, likely reflective of peripheral sensory nerve interactions with immunomodulatory networks (Buchau and Gallo, 2007). Emotional stress is often linked to onset and/or exacerbation of psoriasis (Kiecolt-Glaser et al., 2003), and approximately 40$80 \%$ of psoriatic patients have moderate to severe pruritus (Basavaraj et al., 2011). In addition, the increase in nerve fibers and their secreted neuropeptides involved psoriatic skin (Sugiura et al., 1997), and psoriasis undergoes remission following nerve transection, nerve injury, or decreased nervous system functioning (Shelling et al., 2008).

The skin is highly innervated, in accordance with its role as the "diffuse brain" (Urpe et al., 2005). There is an array of neuropeptides localized in the skin, which includes catecholamines, substance $\mathrm{P}$, calcitonin gene-related peptide, vasoactive intestinal peptide, and nerve growth factor (NGF). However, NGF is recognized as a major mediator inducing nerve fiber expansion. NGF is released from keratinocytes in the skin and its level increases in the epidermis (Raychaudhuri et al., 2000). Strong expression of NGF and its receptors is also observed across the epidermis in a psoriatic lesion (Raychaudhuri et al., 1998). High expression of NGF mediates $\mathrm{T}$ cell and keratinocyte proliferation, mast cell migration, degranulation, and memory $\mathrm{T}$ cell chemotaxis are all hallmarks of psoriasis (Nakamura et al., 2003). These findings suggest that enhanced keratinocyte NGF synthesis seems to stimulate abnormal innervation in the inflammatory skin disease (Taniguchi et al., 2007), although keratinocyte-derived NGF physiologically plays an important role in the maintenance and regeneration of cutaneous nerves in the normal skin (Nithya et al., 2003; Botchkarev et al., 2006).

Studies indicate that NGF may act directly on tyrosine kinase receptors (Trk) expressing vascular precursor cells or indirectly via induction of proangiogenic factors (Kaplan et al., 1991; Klein et al., 1991; Hempstead et al., 1991). In particular, NGF increases the levels of vascular endothelial growth factor (VEGF) in normal neural cells and stimulates angiogenesis in animal models of ischemia (Calza et al., 2001; Cantarella et al., 2002). In psoriasis, overexpression of VEGF can accelerate angiogenesis (Man et al., 2008) and constant delivery of VEGF to the psoriatic skin in the transgenic mouse can result in development of psoriasis-like inflammation (Ren et al., 2009). However, there is limited data about the possible role of NGF regulating VEGF expression in the pathogenesis of psoriasis.

It is reported that transcriptional activation of VEGF and its receptor Flt-1 can be 
achieved by so-called hypoxia-inducible factors (HIF) (Rosenberger et al., 2007) and the increased production of VEGF is dependent on the concomitant induction of HIF-1 $\alpha$ in the pathogenesis of psoriasis (Kim et al., 2011). Therefore, we presumed that in psoriasis lesions, either NGF or VEGF induced the expression of HIF- $1 \alpha$ and the latter facilitated angiogenesis and inflammation in psoriasis. The aim of this study was to determine whether NGF can modulate HIF-1 $\alpha$ /VEGF production at the protein and mRNA levels in the human keratinocyte cell line $\mathrm{HaCaT}$, and identify the intracellular transduction pathways involved in the effect of NGF.

\section{MATERIAL AND METHODS}

\section{Chemicals}

Recombinant NGF was purchased from R\&D Systems (Minneapolis, MN, USA). Dulbecco's modified Eagle's medium (DMEM) was obtained from Gibco (Carlsbad, CA, USA). Antibodies utilized were TrkA inhibitor K252a (Calbiochem, San Diego, CA, USA), anti-human HIF- $1 \alpha$ antibody (BD Transduction Laboratories, San Jose, CA, USA), anti-HIF$2 \alpha$ antibody (Novus Biologicals), anti-HIF-1 $\beta$ antibody (Novus Biologicals), PI3K inhibitor LY294002 (Sigma, St. Louis, MO, USA), MEK inhibitor PD98059 (Sigma), and mTOR inhibitor rapamycin (Cell Signaling Technology, Beverly, MA, USA) were obtained and reconstituted according to manufacturer specifications. The concentration of the VEGF protein was measured using ELISA kits with a mouse monoclonal antibody against human and mouse VEGF (R\&D Systems) according to manufacturer instructions.

\section{Cell culture}

Human keratinocyte cell lines HaCaT cells were cultured in DMEM supplemented with $10 \%$ fetal bovine serum (FBS), $100 \mathrm{U} / \mathrm{mL}$ penicillin, and $100 \mu \mathrm{g} / \mathrm{mL}$ streptomycin. Cells were seeded at a density of $1 \times 10^{6}$ cells $/ 100-\mathrm{mm}$ dishes. After $48 \mathrm{~h}$, the cells were washed with serum-free medium and then replaced with medium without FBS at least $24 \mathrm{~h}$ prior to the experiments. All cells were cultured in a humidified atmosphere containing $5 \% \mathrm{CO}_{2}$ at $37^{\circ} \mathrm{C}$. For hypoxic stimulation, cells were incubated at $5 \% \mathrm{CO}_{2}$ with $1 \% \mathrm{O}_{2}$-balanced $\mathrm{N}_{2}$ in hypoxic chamber (Forma Scientific).

\section{Real-time RT-PCR}

Total RNA was isolated using a Qiagen Extraction procedure. Equal amounts of total RNA $(1 \mu \mathrm{g})$ were reverse-transcribed using the SuperScript ${ }^{\mathrm{TM}}$ III First-Strand Synthesis SuperMix for RT-PCR (Invitrogen, Carlsbad, CA, USA), and the resulting first-strand cDNA was diluted and used as template in the real-time PCR analysis. All measurements were performed in triplicate. Actin served as internal control and was used to normalize the variances in input cDNA. The following primers were used: VEGF forward, 5'-AAGTGGTCCCAGGCTGCA3' and VEGF reverse, 5'-ACTCCAGGCCCTCGTCA-3'; HIF-1 $\alpha$ forward, 5'-AGTCGGACA GCCTCAC-3' and HIF- $1 \alpha$ reverse: 5'-TGCTGCCTTGTATAGGA-3'; $\beta$-actin forward, 5'-GA CACCCACTCCTCCACCTT-3' and $\beta$-actin reverse, 5'-CCACCACCCTGTTGCTGTAG-3'. Detection of the mean band intensities of PCR products were quantified following ethidium 
bromide staining $(\mathrm{N}=3$ ) by using densitometry (Bio-Rad Gel Doc 1000). Densitometry was measured as the level of the densitometry of a specific band.

\section{VEGF ELISA}

The concentration of VEGF in the culture supernatant was measured by a commercially available ELISA. After stimulation, the culture supernatants of cells were collected and added to coated wells. After the addition of diluted biotinylated anti-VEGF antibody to the wells, they were incubated for $90 \mathrm{~min}$ at $37^{\circ} \mathrm{C}$. After washing 4 times with phosphate-buffered saline (PBS)-Tween 20, streptatividin-horseradish peroxidase-conjugated anti-human VEGF antibody was added, and the cells were incubated for $60 \mathrm{~min}$ at $37^{\circ} \mathrm{C}$. The wells were washed 4 times with PBS-Tween 20, and the substrate solution was added, which was incubated for $30 \mathrm{~min}$. Relative absorbance was measured at $450 \mathrm{~nm}$ and the VEGF concentration was calculated using a standard curve. Each supernatant was analyzed in triplicate.

\section{Western blot analysis}

Cells grown on a 10-cm dish were washed with PBS on ice, scraped off with $1 \mathrm{~mL}$ PBS, and collected by centrifugation at $8000 \mathrm{~g}$ for $10 \mathrm{~min}$. After adding $0.1 \mathrm{~mL} 20 \mathrm{mM}$ Tris$\mathrm{HCl}$ buffer, pH 7.4, containing $250 \mathrm{mM}$ sucrose, $2 \mathrm{mM}$ EDTA, $10 \mathrm{mM}$ EGTA, $20 \mu \mathrm{g} / \mathrm{mL}$ leupeptin, $1 \mathrm{mM}$ PMSF, and $0.25 \%$ Tween 20 , the cells were lysed on ice by sonication and then centrifuged at 12,000 $\mathrm{g}$ for $10 \mathrm{~min}$ to obtain cell extracts. Protein concentrations were determined using the BCA Protein Assay Kit (Thermo Fisher Scientific, Inc., Rockford, IL, USA). Approximately $70 \mu \mathrm{g}$ protein was subjected to $8 \%$ SDS-PAGE and electrophoretically transferred to nitrocellulose membranes. Membranes were blocked in 5\% nonfat milk in PBS$\mathrm{T}(0.03 \%$ Triton X-100 in PBS) and then incubated with anti-HIF- $1 \alpha$ antibody/HIF- $\alpha / \mathrm{HIF}-1 \beta$ antibody or anti-TrkA/PI3K/MEK/mTOR antibody as the first antibody for $1 \mathrm{~h}$. Membranes were then washed 3 times with PBS-T and incubated with the secondary antibody conjugated with anti-rabbit or anti-mouse horseradish peroxidase (Jackson Immuno-Research, West Grove, PA, USA) for $30 \mathrm{~min}$. Bands were visualized by using the enhanced chemiluminescent Western Blotting Detection Reagents (GE Healthcare, Buckinghamshire, UK).

\section{RNA interference (RNAi)}

Oligonucleotides for RNAi were purchased from MWG-Biotech (Ebersberg, Germany). The interference RNA (siRNA) were synthesized and high-performance liquid chromatography purified at Transgenomic Laboratories (Anhui Huabao Biology Co., Ltd., Hefei, China). DNA plasmids were prepared using a commercially available kit (Endofree Maxi-Prep; Qiagen). Transfections were performed using Lipofectamine 2000 (Invitrogen) according to manufacturer instructions. After $16 \mathrm{~h}$, the protein lysates were made and luciferase assays were performed on 96-well optiplates (Packard Instrument, Inc., Meriden, CT, USA) as previously described (Matsuo et al., 2000). The HIF-1 $\alpha$ small siRNA (AAAGGACAAGTCACCACAGGA) to target HIF-1 $\alpha$ and a nonspecific siRNA control (AATTCTCCGAACGTGTCACGT) were utilized. After $24 \mathrm{~h}$, the cell supernatants were collected and evaluated for VEGF protein expression by ELISA while the cells were lysed 
with buffer containing 1\% NP-40 and protein expression evaluated by Western blot analysis. Luciferase assays were performed on 96-well optiplates.

\section{Statistical analysis}

Data are reported as means $\pm \mathrm{SE}$. The statistical significance was calculated by the 2 -sample independent-group $t$-test. $\mathrm{P}<0.05$ was considered to be significant.

\section{RESULTS}

\section{NGF induces mRNA expression and production of VEGF in HaCaT}

To study the effect of NGF on VEGF mRNA expression in HaCaT cells, the cells were treated with the exogenous NGF $(0-10 \mathrm{IU} / \mathrm{mL})$. Total RNA was extracted after $6 \mathrm{~h}$ and realtime PCR for VEGF was performed. VEGF mRNA expression was significantly increased by NGF (Figure 1A). VEGF production was measured from supernatants of NGF-treated cultured $\mathrm{HaCaT}$ cells collected $12 \mathrm{~h}$ after the exposure (Figure 1B). Induction of the VEGF protein level was concentration-dependent, with the maximal effect at $10 \mathrm{IU} / \mathrm{mL}$. These data demonstrated that NGF strongly upregulates VEGF mRNA and protein levels in HaCaT cells.
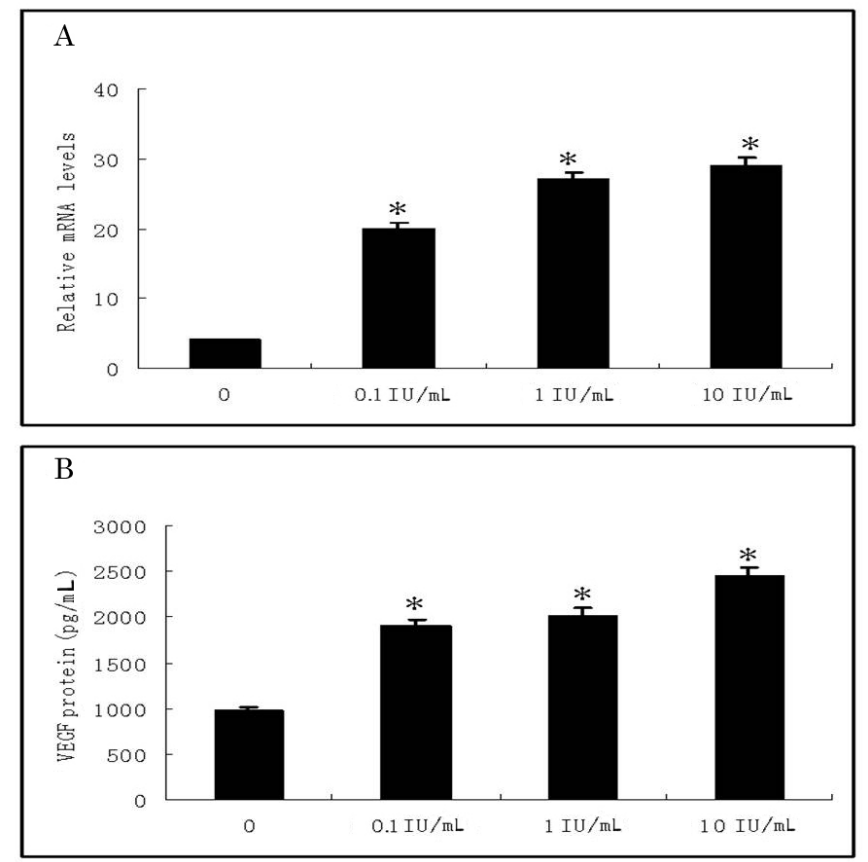

Figure 1. Different concentrations of nerve growth factor (NGF: 0-10 IU/mL) induce mRNA expression and production of vascular endothelial growth factor (VEGF) in $\mathrm{HaCaT}$ keratinocytes. A. HaCaT cells were harvested after NGF treatment for $6 \mathrm{~h}$. Total RNA was extracted, and VEGF mRNA transcript levels were determined by real-time RT-PCR. B. Cells were treated with indicated concentrations of NGF for $12 \mathrm{~h}$. Cell supernatants were collected and then VEGF concentration was measured by ELISA; each performed in triplicate. Data are reported as means $\pm \mathrm{SE}(* \mathrm{P}<0.05)$. 


\section{Effect of NGF on HIF-1a protein levels of HaCaT}

HaCaT were exposed to different concentrations $(0-10 \mathrm{IU} / \mathrm{mL})$ of NGF for $24 \mathrm{~h}$,. As shown in Figure 2A, when the HaCaT were treated with NGF pre-determined for $24 \mathrm{~h}$, the expression of hypoxia-induced HIF-1 $\alpha$ was significantly increased in a dose-dependent manner. However, under these conditions, the levels of HIF- $2 \alpha$ and HIF- $1 \beta$ are unchanged. Although NGF upregulated the level of hypoxia-induced HIF-1 $\alpha$ protein, it did not affect its mRNA expression (Figure 2B). These data suggest that NGF elevates the stability of the HIF-1 $\alpha$ protein.

A

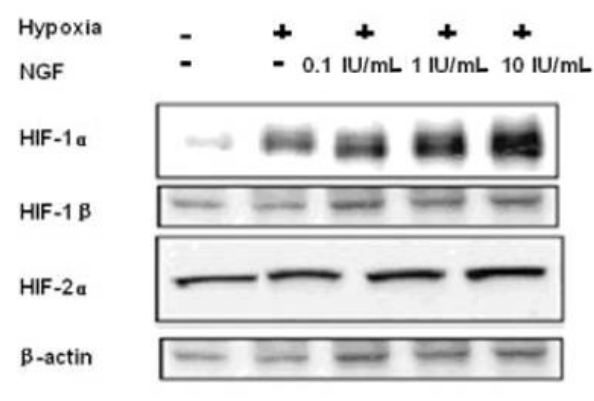

$\mathrm{C}$

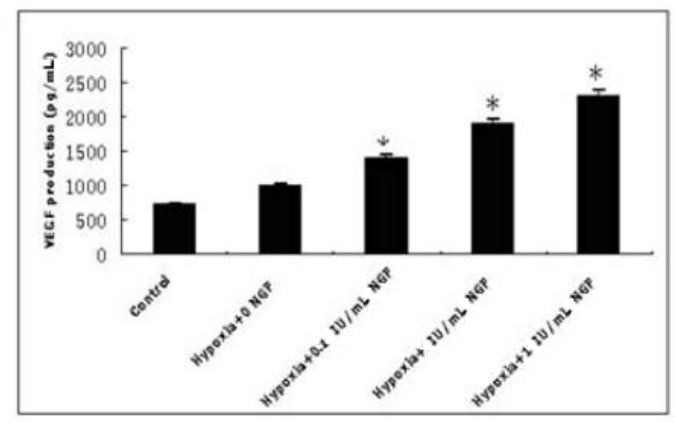

B

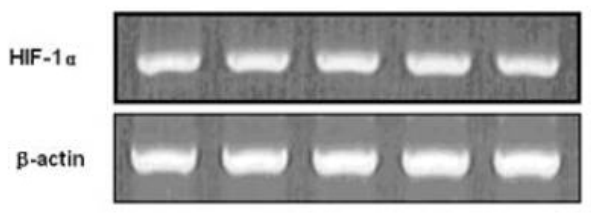

$\mathrm{D}$

Figure 2. Nerve growth factor (NGF) regulates HIF-1 $\alpha$ levels in HaCaT keratinocytes. A. Western analysis of total protein lysates $(30 \mu \mathrm{g})$ from indicated $\mathrm{HaCaT}$ cells treated for $16 \mathrm{~h}$ with normoxia or hypoxia or different concentrations of NGF $(0-10 \mathrm{IU} / \mathrm{mL})$ for HIF- $1 \alpha$, HIF- $2 \alpha$ and HIF-1 $\beta$ levels. B. RT-PCR was performed using specific primer for HIF-1 $\alpha ; \beta$-actin served as loading control. C. Cells were incubated with different concentrations of NGF (0-10 IU/ $\mathrm{mL}$ ) for $12 \mathrm{~h}$ under normoxia or hypoxia condition. Cell supernatants were collected and then VEGF concentration was measured by ELISA; each performed in triplicate. Data are reported as means $\pm \mathrm{SE}\left({ }^{*} \mathrm{P}<0.05\right)$. $\mathbf{D}$. VEGF mRNA transcript levels were determined by real-time RT-PCR. Normoxia condition and 0 NGF served as control in $\mathbf{C}$ and $\mathbf{D}$.

Furthermore, to study whether the promotion of the HIF-1 $\alpha$ protein related with activation of hypoxia-induced angiogenesis, we examined the expression of the VEGF protein and mRNA by treatment with NGF under hypoxia. Figure $2 \mathrm{C}$ and $\mathrm{D}$ show that the NGF gradually upregulated the expression of hypoxia-induced VEGF protein and mRNA in a dose-dependent manner. This means that the upregulation of VEGF by NGF may be due to the activation of HIF-1 $\alpha$ activity. 


\section{MAPK and mTOR pathway are involved in NGF-induced VEGF production}

Initial studies were performed to determine the effect of the MAPK inhibitor and the mTOR inhibitor on mRNA transcription of VEGF. HaCaT cells were treated with either the antagonist of MAPK pathway (PD98059) or an inhibitor of mTOR (rapamycin) at a concentration of $10 \mathrm{IU} / \mathrm{mL}$ for $2 \mathrm{~h}$, prior to the addition of NGF and the expression of VEGF mRNA transcript was assessed. The effect of PD98095 and rapamycin on VEGF protein secretion was also detected. As shown in Figure 3, pretreatment of HaCaT cells with either PD98095 or rapamycin for $2 \mathrm{~h}$ before the addition of $10 \mathrm{IU} / \mathrm{mL}$ NGF significantly inhibited NGF-increased VEGF mRNA expression and its production.
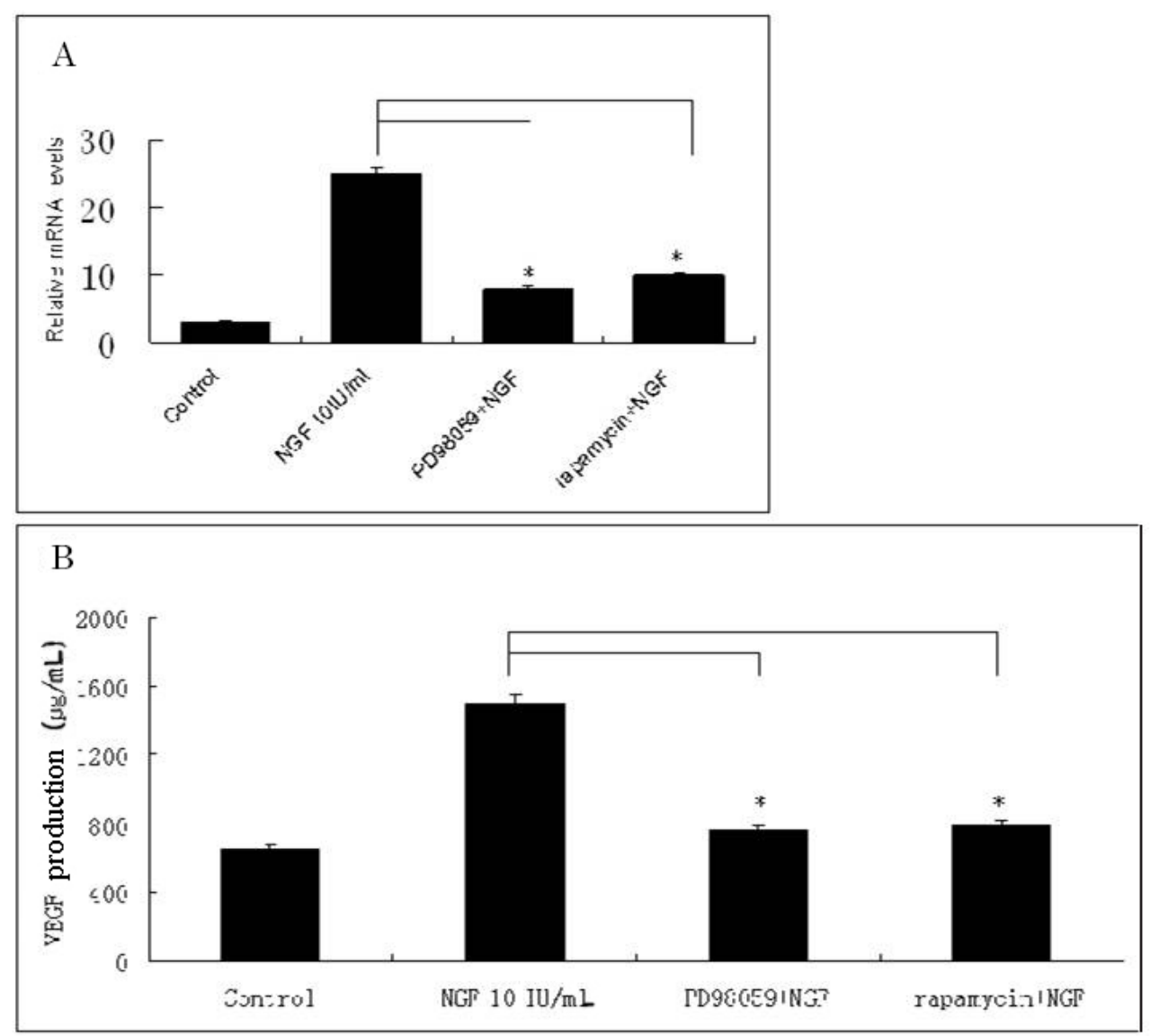

Figure 3. MAPK antagonist PD98059 and the mTOR inhibitor rapamycin inhibit mRNA expression and production of VEGF in NGF-treated HaCaT keratinocytes. A. HaCaT cells were stimulated with or without $10 \mathrm{IU} / \mathrm{mL}$ NGF for $6 \mathrm{~h}$ after treatment with PD98059 or rapamycin for $2 \mathrm{~h}$. Total RNA was extracted, and VEGF mRNA transcript levels were determined by real-time RT-PCR. B. Cells were incubated with rapamycin or PD 98059 for $2 \mathrm{~h}$ prior to the addition of $10 \mathrm{IU} / \mathrm{mL}$ NGF for $12 \mathrm{~h}$. Cell supernatants were collected and then VEGF concentration was measured by ELISA; each performed in triplicate. Data are reported as means $\pm \mathrm{SE}(* \mathrm{P}<0.05)$. 


\section{Signal transduction pathway of NGF/mTOR}

To evaluate the signal transduction pathway that contributes to the NGF-induced HIF-1 $\alpha$ and VEGF expression in HaCaT cells, we used pharmacologic inhibitors of the TrkA (K252a), MAPK pathway (PD98059), PI3K (LY294002), and mTOR (rapamycin). When HaCaT cells were treated with NGF following pretreatment with K252a, LY294002, or rapamycin, NGF-induced HIF-1 $\alpha$ expression was markedly inhibited (Figure 4A). Moreover, pretreatment with PD98059, the MAPK inhibitor, partially inhibited the NGF-induced HIF-1 $\alpha$ expression (Figure 4A). Consistent with inhibition of HIF-1 $\alpha$ protein, K252a, LY294002, and rapamycin blocked the NGF-induced VEGF protein secretion from $\mathrm{HaCaT}$ cells. PD98059 partially inhibited the VEGF secretion $(* \mathrm{P}<0.05, * * \mathrm{P}<0.01$; Figure $4 \mathrm{~B})$. These findings indicate that the PI3K/mTOR pathway markedly decreased the expression of HIF-1 $\alpha$, which leads to the decrease in VEGF expression.

A

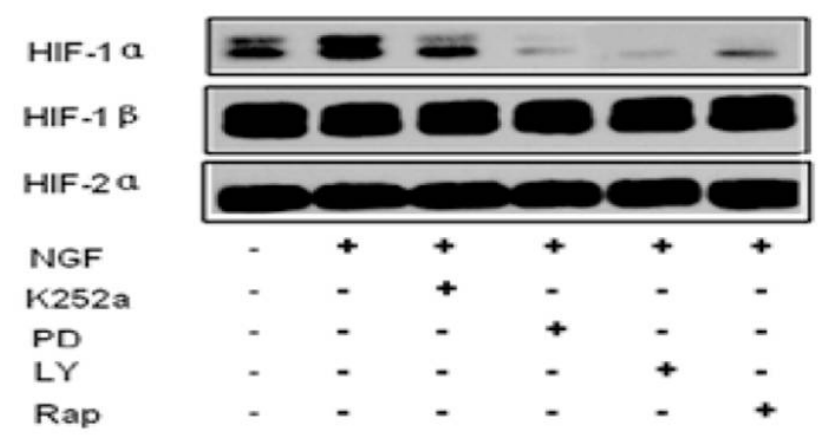

B

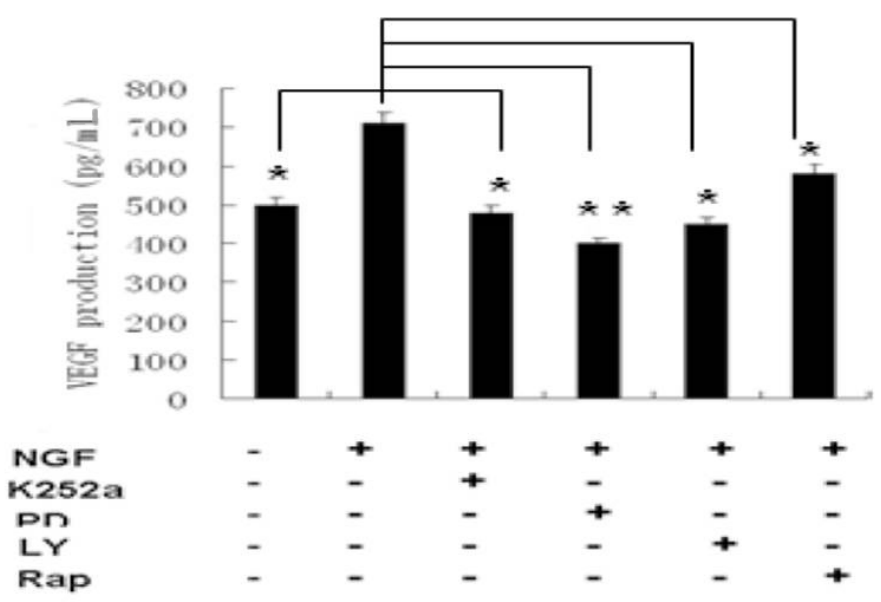

Figure 4. Nerve growth factor (NGF) regulates HIF-1 $\alpha$ and VEGF levels via PI3K/mTOR and MAPK pathways. A. Western analysis of $30 \mu \mathrm{g} \mathrm{HIF-1} \alpha$ levels in protein lysates from the HaCaT cells pretreated with control solvent or indicated inhibitor for $1 \mathrm{~h}$ followed by stimulation with NGF for $8 \mathrm{~h}$. HIF- $2 \alpha$ is shown as a loading control. B. Conditioned media from the HaCaT cells incubated with serum-free media for $6 \mathrm{~h}$ following a 1-h preincubation with control solvent or indicated inhibitor are analyzed by ELISA for VEGF expression. Data are reported as means \pm SE of triplicate values for each condition $(* \mathrm{P}<0.05, * * \mathrm{P}<0.01)$. 


\section{siRNA knockdown of HIF-1 $\alpha$ decreases VEGF protein expression}

To directly evaluate whether HIF-1 $\alpha$ plays a role in NGF/mTOR-stimulated VEGF protein expression, we transfected an HIF-1 $\alpha$ siRNA or a control siRNA into the HaCaT cells and cultured it for $24 \mathrm{~h}$ in NGF $(10 \mathrm{IU} / \mathrm{mL})$. Western blot analysis indicated that HIF-1 $\alpha$ protein expression decreased in cells transfected with the HIF-1 $\alpha$ siRNA compared to cells transfected with the control siRNA treated with NGF (Figure 5A). Furthermore, HIF-1 $\alpha$ siRNA knockdown caused a $42 \%$ decrease in NGF-induced transcriptional activity in the HaCaT cells (Figure 5B). When VEGF protein levels were measured in the supernatants from these samples, the NGF-stimulated VEGF protein levels decreased by approximately $47 \%$ in the HIF-1 $\alpha$ siRNA-transfected samples compared to the control siRNA-transfected samples (Figure 5C). These results indicate that a large portion of the NGF-induced VEGF expression is regulated by HIF-1 $\alpha$ in this system.

$\mathrm{A}$

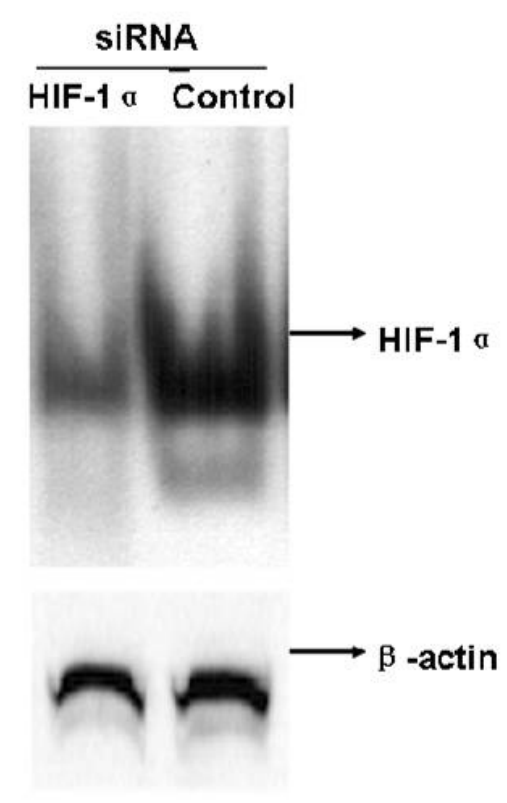

B

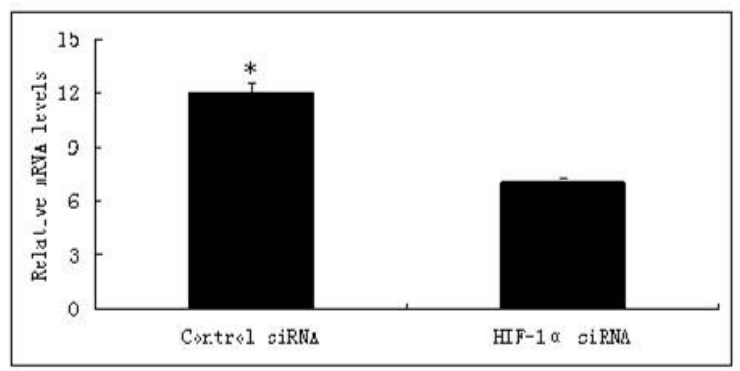

$\mathrm{C}$

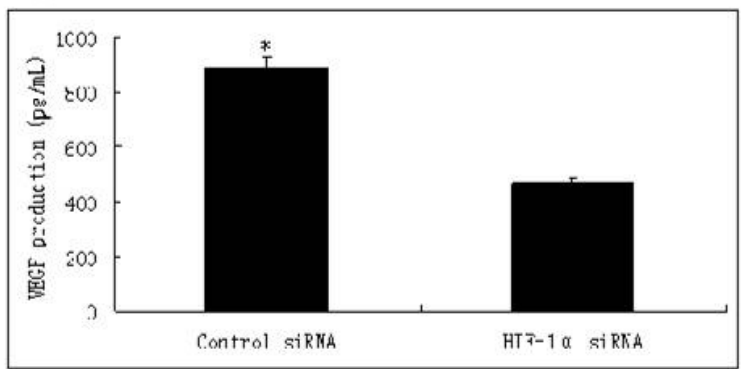

Figure 5. HIF-1 $\alpha$ siRNA knockdown of VEGF protein expression. A. Western analysis of total protein lysates (30 $\mu \mathrm{g}$ ) from the HaCaT cells transfected control siRNA or HIF-1 $\alpha$ siRNA with $10 \mathrm{IU} / \mathrm{mL}$ NGF after $24 \mathrm{~h}$ for HIF-1 $\alpha$ and $\beta$-actin levels. B. Luciferase activity from the HaCaT cells $\left(1 \times 10^{6}\right)$ with control siRNA or HIF-1 $\alpha$ siRNA treated with NGF $(10 \mathrm{IU} / \mathrm{mL})$ for $24 \mathrm{~h}$ was analyzed by luciferase assay. Results are reported as means $\pm \mathrm{SE}$ of triplicate values for each condition $(* \mathrm{P}<0.05)$. C. VEGF protein levels were analyzed by ELISA. Data are reported as means $\pm \mathrm{SE}$ of triplicate values for each condition $(* \mathrm{P}<0.05)$.

\section{DISCUSSION}

NGF is a chemotactic factor for nerve cells and keratinocyte-derived NGF is thought 
to play an important role in normal maintenance, proliferation, and differentiation of not only cutaneous nerves, but also keratinocytes, melanocytes, and other cells in the skin (Marconi et al., 1999; Montano et al., 2010). Cellular responses to NGF are mediated by 2 classes of transmembrane receptors, a low-affinity receptor of $\sim 75 \mathrm{kD}$ (p75) (Johnson et al., 1986) and a highaffinity tyrosine kinase receptor of $\sim 140 \mathrm{kD}$ (TrkA) (Kaplan et al., 1991). In psoriasis, NGF can have a pleiotropic role in the pathogenesis by regulating nerve growth, neuropeptides, angiogenesis, cell trafficking, and the function of T cells and mast cells, as recently reviewed (Raychaudhuri and Raychaudhuri, 2009). The HaCaT cell line has been widely used for the in vitro testing of antipsoriatic compounds (Muller and Prinz, 1997; Geilen et al., 1997). Therefore, in this study, we detail the mechanisms of neurotrophin-mediated induction of VEGF in $\mathrm{HaCaT}$ cell lines. Here, we, for the first time, showed that NGF enhanced the expression of HIF- $1 \alpha$ and VEGF in HaCaT keratinocytes. NGF stimulates increases in VEGF production that is accompanied by increases in HIF- $1 \alpha$, but not in HIF-1 $1 \beta$ or HIF- $2 \alpha$. Moreover, pharmacologic inhibition of the Trk tyrosine kinase, PI-3 kinase, or mTOR pathways blocks NGF-induced increases in HIF-1 $\alpha$ and VEGF production. These data are similar with previous findings in neural cell lines which brain-derived neurotrophic factor (BDNF) activation of a TrkB/PI-3kinase/AKT/mTOR pathway increases VEGF production via induction of HIF-1 $\alpha$ dependent increases in VEGF promoter activity (Nakamura et al., 2006).

An important aspect of our study is the finding that the effect of NGF was antagonized by a specific inhibitor of the mTOR pathway (rapamycin). The current results show that NGF is able to increase VEGF secretion and mRNA level in human keratinocyte cell lines. Similar results were obtained with calcitonin gene-related peptide, which increased VEGF expression in human HaCaT keratinocytes, and the ERK 1/2 MAPK signaling pathways of VEGF expression, which was explored by calcitonin gene-related peptide in $\mathrm{HaCaT}$ (Yu et al., 2006). In addition, substance $\mathrm{P}$ increased VEGF expression in human prostate cancer LNCaP cells (Castellani et al., 2010). In particular, Takaoka et al. (2009) suggested that tumor necrosis factor (TNF)- $\alpha$, an inflammatory cytokine, enhanced NGF production via the Raf-1/MEK/ERK pathway in human keratinocytes (Takaoka et al., 2009). However, our results suggest that the effect of NGF was antagonized both by MAPK receptor antagonist (PD98059) and by a specific inhibitor of the mTOR pathway (rapamycin). The mTOR has been reported to regulate the expression of several cytokines. In addition, mTOR is activated by various stimuli, including growth factor receptors, G-protein-coupled receptors, inflammatory cytokine receptors, and induction of stress by ultraviolet light or high osmolarity (Lappano and Maggiolini, 2011). More recently, it was reported that NGF could induce VEGF expression in human keratinocytes, and that the mechanism of VEGF expression might be through a pathway in which NGF activated HIF- $1 \alpha$ via the MAPK and mTOR pathway in TrkA-expressing TA25 cells (Nakamura et al., 2011). Harmacologic inhibition of Trk (K252a), the PI3-kinase/mTOR, and to a lesser extent, the MAPK pathway decreased HIF-1 $\alpha$ expression to a level lower than basal HIF- $1 \alpha$ levels only prevented NGF-mediated increases in VEGF production. The inhibition of mTOR does not fully abolish the NGF effect on VEGF production, suggesting that other intracellular pathways could be involved. Thus, other signaling pathways should probably be investigated in future studies. Examining the signaling systems stimulated by NGF will give us a better understanding of the complexity of actions of NGF.

We demonstrate that NGF causes a concentration-dependent increase in VEGF and HIF-1 $\alpha$ activity in HaCaT keratinocytes. Previous studies have investigated that both VEGF 
and HIF- $1 \alpha$ are likely key factors in the link between inflammation and angiogenesis in psoriasis and regarded as the new potential target for the therapy of psoriasis (Rosenberger et al., 2007). Overexpression of VEGF and HIF-1 $\alpha$ has a synergistic effect on angiogenesis in psoriasis, and therefore, NGF and NGF-induced VEGF may both contribute to psoriatic angiogenesis. The current results show that the neurotrophin-mediated increases in VEGF are dependent on the increases in HIF-1 $\alpha$. These results are consistent with reports in which VEGF transcription is attenuated if the VEGF promoter contains a mutation in the hypoxic response element that is known to disrupt HIF-1 $\alpha$ transcription factor binding (Kwon et al., 2004). Furthermore, an siRNA targeted to HIF-1 $\alpha$ blocks the ability of NGF to stimulate increases in VEGF transcription and causes a reduction in VEGF production in the $\mathrm{HaCaT}$ cells (Figure 5).

In conclusion, our results suggest that NGF induces the expression of an angiogenic factor, VEGF, which is involved in the pathogenesis of psoriasis, through the MAPK and mTOR pathway. In addition, the NGF-induced increase in VEGF is correlated with an increase in HIF-1 $\alpha$ under hypoxia condition in HaCaT cells. This finding may provide an insight into the pathophysiology of neuroinflammatory skin diseases such as psoriasis.

\section{REFERENCES}

Basavaraj KH, Navya MA and Rashmi R (2011). Stress and quality of life in psoriasis: an update. Int. J. Dermatol. 50: 783-792.

Botchkarev VA, Yaar M, Peters EM, Raychaudhuri SP, et al. (2006). Neurotrophins in skin biology and pathology. J. Invest. Dermatol. 126: 1719-1727.

Buchau AS and Gallo RL (2007). Innate immunity and antimicrobial defense systems in psoriasis. Clin. Dermatol. 25: 616-624.

Calza L, Giardino L, Giuliani A, Aloe L, et al. (2001). Nerve growth factor control of neuronal expression of angiogenetic and vasoactive factors. Proc. Natl. Acad. Sci. U. S. A. 98: 4160-4165.

Cantarella G, Lempereur L, Presta M, Ribatti D, et al. (2002). Nerve growth factor-endothelial cell interaction leads to angiogenesis in vitro and in vivo. FASEB J. 16: 1307-1309.

Castellani ML, Galzio RJ, Felaco P, Tripodi D, et al. (2010). VEGF, substance P and stress, new aspects: a revisited study. J. Biol. Regul. Homeost. Agents 24: 229-237.

Geilen CC, Bektas M, Wieder T, Kodelja V, et al. (1997). 1 $\alpha$, 25-dihydroxyvitamin D3 induces sphingomyelin hydrolysis in HaCaT cells via tumor necrosis factor $\alpha$. J. Biol. Chem. 272: 8997-9001.

Hempstead BL, Martin-Zanca D, Kaplan DR, Parada LF, et al. (1991). High-affinity NGF binding requires coexpression of the trk proto-oncogene and the low-affinity NGF receptor. Nature 350: 678-683.

Johnson D, Lanahan A, Buck CR, Sehgal A, et al. (1986). Expression and structure of the human NGF receptor. Cell 47: 545-554.

Kaplan DR, Hempstead BL, Martin-Zanca D, Chao MV, et al. (1991). The trk proto-oncogene product: a signal transducing receptor for nerve growth factor. Science 252: 554-558.

Kiecolt-Glaser JK, Preacher KJ, MacCallum RC, Atkinson C, et al. (2003). Chronic stress and age-related increases in the proinflammatory cytokine IL-6. Proc. Natl. Acad. Sci. U. S. A. 100: 9090-9095.

Kim Y, Kim BH, Lee H, Jeon B, et al. (2011). Regulation of skin inflammation and angiogenesis by EC-SOD via HIF-1 $\alpha$ and NF-к $\beta$ pathways. Free Radic. Biol. Med. 51: 1985-1995.

Klein R, Jing SQ, Nanduri V, O'Rourke E, et al. (1991). The trk proto-oncogene encodes a receptor for nerve growth factor. Cell 65: 189-197.

Kwon YW, Kwon KS, Moon HE, Park JA, et al. (2004). Insulin-like growth factor-II regulates the expression of vascular endothelial growth factor by the human keratinocyte cell line HaCaT. J. Invest. Dermatol. 123: 152-158.

Lappano R and Maggiolini M (2011). G protein-coupled receptors: novel targets for drug discovery in cancer. Nat. Rev. Drug Discov. 10: 47-60.

Man XY, Yang XH, Cai SQ, Bu ZY, et al. (2008). Overexpression of vascular endothelial growth factor (VEGF) receptors on keratinocytes in psoriasis: regulated by calcium independent of VEGF. J. Cell Mol. Med. 12: 649-660.

Marconi A, Vaschieri C, Zanoli S, Giannetti A, et al. (1999). Nerve growth factor protects human keratinocytes from 
ultraviolet-B-induced apoptosis. J. Invest. Dermatol. 113: 920-927.

Matsuo T, Stauffer JK, Walker RL, Meltzer P, et al. (2000). Structure and promoter analysis of the human unc-33-like phosphoprotein gene. E-box required for maximal expression in neuroblastoma and myoblasts. J. Biol. Chem. 275: 16560-16568.

Menter A and Griffiths CE (2007). Current and future management of psoriasis. Lancet 370: 272-284.

Montano JA, Pérez-Pinera P, García-Suárez O, Cobo J, et al. (2010). Development and neuronal dependence of cutaneous sensory nerve formations: Lessons from neurotrophins. Microsc. Res. Tech. 73: 513-529.

Muller K and Prinz H (1997). Antipsoriatic anthrones with modulated redox properties. 4. Synthesis and biological activity of novel 9, 10-dihydro-1, 8-dihydroxy-9-oxo-2-anthracenecarboxylic and -hydroxamic acids. J. Med. Chem. 40: 2780-2787.

Nakamura M, Toyoda M and Morohashi M (2003). Pruritogenic mediators in psoriasis vulgaris: comparative evaluation of itch-associated cutaneous factors. Br. J. Dermatol. 149: 718-730.

Nakamura K, Martin KC, Jackson JK, Beppu K, et al. (2006). Brain-derived neurotrophic factor activation of TrkB induces vascular endothelial growth factor expression via hypoxia-inducible factor-1 $\alpha$ in neuroblastoma cells. Cancer Res. 66: 4249-4255.

Nakamura K, Tan F, Li Z and Thiele CJ (2011). NGF activation of TrkA induces vascular endothelial growth factor expression via induction of hypoxia-inducible factor-1 $\alpha$. Mol. Cell Neurosci. 46: 498-506.

Nestle FO, Kaplan DH and Barker J (2009). Psoriasis. N. Engl. J. Med. 361: 496-509.

Nithya M, Suguna L and Rose C (2003). The effect of nerve growth factor on the early responses during the process of wound healing. Biochim. Biophys. Acta 1620: 25-31.

Raychaudhuri SK and Raychaudhuri SP (2009). NGF and its receptor system: a new dimension in the pathogenesis of psoriasis and psoriatic arthritis. Ann. N. Y. Acad. Sci. 1173: 470-477.

Raychaudhuri SP, Jiang WY and Farber EM (1998). Psoriatic keratinocytes express high levels of nerve growth factor. Acta Derm. Venereol. 78: 84-86.

Raychaudhuri SP, Jiang WY, Smoller BR and Farber EM (2000). Nerve growth factor and its receptor system in psoriasis. Br. J. Dermatol. 143: 198-200.

Ren X, Li J, Zhou X, Luo X, et al. (2009). Recombinant murine interleukin 4 protein therapy for psoriasis in a transgenic VEGF mouse model. Dermatology 219: 232-238.

Rosenberger C, Solovan C, Rosenberger AD, Jinping L, et al. (2007). Upregulation of hypoxia-inducible factors in normal and psoriatic skin. J. Invest. Dermatol. 127: 2445-2452.

Shelling ML, Federman DG, Prodanovich S and Kirsner RS (2008). Psoriasis and vascular disease: an unsolved mystery. Am. J. Med. 121:360-365.

Sugiura H, Omoto M, Hirota Y, Danno K, et al. (1997). Density and fine structure of peripheral nerves in various skin lesions of atopic dermatitis. Arch. Dermatol. Res. 289: 125-131.

Takaoka K, Shirai Y and Saito N (2009). Inflammatory cytokine tumor necrosis factor- $\alpha$ enhances nerve growth factor production in human keratinocytes, HaCaT cells. J. Pharmacol. Sci. 111: 381-391.

Taniguchi M, Matsuzaki S and Tohyama M (2007). P75 plays a key role in the induction of the sprouting of sensory nerve fibers in inflamed skin. J. Invest. Dermatol. 127: 2062-2065.

Urpe M, Buggiani G and Lotti T (2005). Stress and psychoneuroimmunologic factors in dermatology. Dermatol. Clin. 23: 609-617.

Yu XJ, Li CY, Wang KY and Dai HY (2006). Calcitonin gene-related peptide regulates the expression of vascular endothelial growth factor in human HaCaT keratinocytes by activation of ERK1/2 MAPK. Regul. Pept. 137: 134-139. 